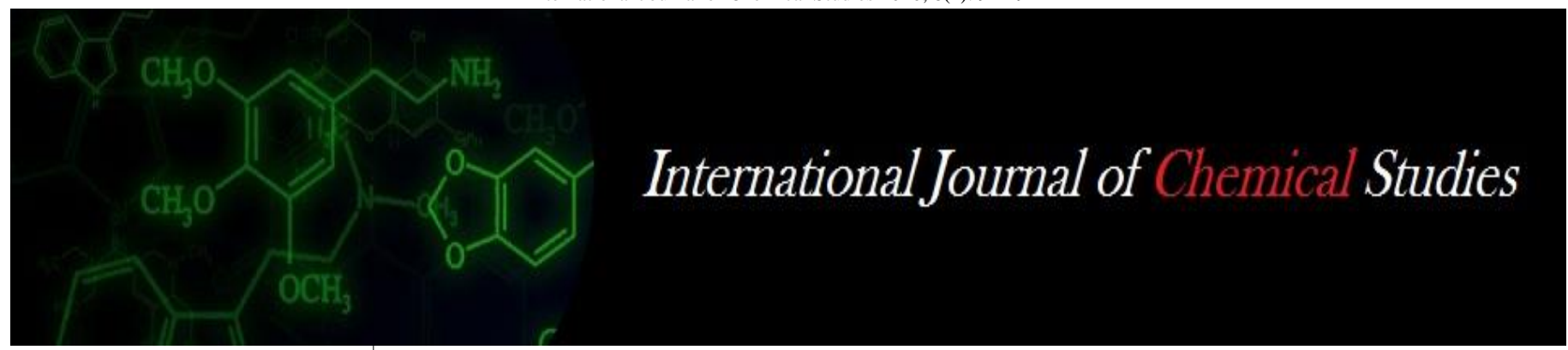

P-ISSN: 2349-8528

E-ISSN: 2321-4902

www.chemijournal.com

IJCS 2020; 8(4): 921-924

(C) 2020 IJCS

Received: 13-05-2020

Accepted: 15-06-2020

Gurdarshan Singh

Associate Professor

(Horticulture) KVK Faridkot,

Punjab, India

Jagdish Grover

Associate Director, KVK

Faridkot, Punjab, India

Corresponding Author:

Gurdarshan Singh

Associate Professor

(Horticulture) KVK Faridkot,

Punjab, India

\section{Influence of nodal pruning on vegetative and reproductive attributes of Sardar guava}

\author{
Gurdarshan Singh and Jagdish Grover
}

DOI: https://doi.org/10.22271/chemi.2020.v8.i4f.9722

\begin{abstract}
Investigations on "Influence of nodal pruning on vegetative and reproductive attributes of Sardar guava" were carried out in the orchard of Amarjit Singh at village Bargari in district Faridkot of South-Western Punjab. Pruning intensities consisted of removal of shoot tip up to $0,4^{\text {th }}, 6^{\text {th }}$ and $8^{\text {th }}$ node. There were five replications and the data were analyzed using Randomized Block Design. As per university recommendation, farmers are advised to opt for light pruning in guava, i.e., removal of shoot tip up to 10 $\mathrm{cm}$ in first fortnight of March. However, guava orchardists are of the view that pruning levels should be in terms of how many nodes to prune as it is easier for them to guide the pruning labor in terms of number of nodes to be pruned rather than in centimeters. To ascertain the above facts, On Farm Trial was conducted to find out the effect of nodal pruning on vegetative and reproductive attributes of Sardar guava. The results of investigation revealed that with the increase in severity of pruning, there was significant increase in shoot length. Severe pruning minimized the span of flowering as severe pruning level of 8-node pruning intensity recorded the shortest duration of flowering during both the rainy and winter season crops of both the years. Although, there was increment in fruit set with the enhanced severity of pruning, the results were non significant. 6-node pruning intensity recorded significantly higher fruit yield per tree during both the cropping seasons of both the years. There was significant increase in fruit weight with the increase in severity of pruning during the rainy and winter season crops of both the years. TSS/Acid ratio was not altered much by pruning intensity. On the other, there was a significant increase in ascorbic acid content of the fruits with the enhanced severity of pruning. On the whole, pruning to 6 nodes gave the highest fruit yield and accounted for production of fruits of good quality.
\end{abstract}

Keywords: Guava, nodal pruning, pruning intensity, fruit yield, TSS/Acid ratio and Ascorbic acid content.

\section{Introduction}

Guava (Psidium guajava L.), the "Apple of the tropics" or "Poor man's apple" is one of the most popular fruit crops of tropical and subtropical climate belonging to Myrtaceae family (Radha and Mathew, 2007). It is the third richest source of Vitamin C (299 mg/100g) after Barbados cherry (1000-4000 mg/100 g pulp) and aonla $(600 \mathrm{mg} / 100 \mathrm{~g}$ of pulp).According to Gupta (2014), guava contains 2 to 5 times more vitamin $C$ than oranges and 10 times more than tomato. Guava is hardy, prolific bearer and highly remunerative fruit crop grown on a variety of soils under varied agro-climatic conditions. In India, it is being cultivated on 2, 65,000 ha with production of 40, 54, 000 MT (Anon, 2018). In Punjab and most of the other parts of Northern India, it flowers once in April- May for the rainy season crop and again in August-September for the winter season crop. Flowers are borne solitary or in cymes of two or three flowers, on the current season's growth which necessitates the replacing of old wood by the new one by pruning Moreover, observations have shown that after 8-10 years of age, guava trees show considerable decline in yield with sub-optimal fruit quality owing to vigorous vegetative growth and frequent intermingling of the branches particularly in the lower half of the tree leading to unfruitfulness, as fruitful buds become blind. Such unproductive trees can be made to bear profitable crop for more years by judicious pruning. Thus, pruning influences the vigor, productivity and quality of the fruits.

The results of studies have indicated that whenever pruning has been attempted in guava, there has been noticed vast improvement in yield and fruit quality, especially, with light pruning (Bajpai et al 1973). On the other hand, Jadhao et al (1998) reported that severe pruning 
(60 $\mathrm{cm}$ from the tip) resulted in the most vigorous vegetative growth and the highest fruit yield in guava. Punjab Agricultural University, Ludhiana has recommended light pruning in guava, i.e., removal of shoot tip up to $10 \mathrm{~cm}$ in first fortnight of March. However, guava orchardists are of the view that they must be disseminated the recommendation in terms of how many nodes to prune as it is easier for them to guide the pruning labor in terms of number of nodes to be pruned rather than in centimeters. To ascertain the above facts, On Farm Trial was conducted to find out the influence of nodal pruning on vegetative and reproductive attributes of Sardar guava.

\section{Research Methodology}

The present study was conducted on ten year-old grafted plants of Sardar guava planted $6 \mathrm{~m}^{2}$ apart in the guava orchard of Amarjit Singh of village Bargari in district Faridkot of Punjab. The pruning treatments were applied in the first week of March 2017 and 2018, with four pruning levels, i.e., removal of shoot tip up to $0,4^{\text {th }}, 6^{\text {th }}$ and $8^{\text {th }}$ node. There were five replications. The observations on increase in shoot length, duration of flowering, fruit set and fruit yield, TSS: Acid ratio and ascorbic acid content were recorded. The TSS was recorded by Bausch and Lomb (0-32) refractrometer. Per cent acidity was expressed in terms of anhydrous citric acid per $100 \mathrm{ml}$ of juice by using the following formula:

Per cent acidity $=0.0064 \times 0.1 \mathrm{~N} \mathrm{NaOH}$ used $(\mathrm{ml}) /$ juice taken (ml) x 100

The ascorbic acid content was calculated by using the formula cited below:

Ascorbic acid $(\mathrm{mg} / 100 \mathrm{~g}$ of pulp weight $)=\frac{\text { volume of standard ascorbic acid }}{\text { volume of dye used for standard ascorbic acid }} \times \frac{\text { volume of dye used for titration of juice }}{\text { volume of juice }}$

\section{Research findings and discussion}

\section{Effect of pruning on vegetative attributes}

The data presented in Table 1 revealed that there was enhancement in vegetative growth with the increase in pruning intensity. Trees subjected to 8-node pruning level registered the maximum shoot length during both the rainy and winter season crops of both the years and it was significantly higher than the shoot length under all other treatments. The highest net increase in shoot length in severely pruned trees might be due to the quick response of supply of food material absorbed by the roots and transmission of the same to the shoots of such trees. Moreover, in such trees most of the carbohydrates and nitrogen were utilized for the vegetative growth, thereby, resulting in stimulated production of leader and lateral shoots, ultimately accounting for increased canopy volume. The results of present study are in conformity with those of Dasarathy (1951), Aravindakshan (1953) and Gill (1994). Bhagawati et al. (2015) attributed this increment in shoot length under severe pruning to relatively less number of shoots and availability of more nutrients per shoots.

Table 1: Influence of pruning intensity on shoot length $(\mathrm{cm})$ in Sardar guava

\begin{tabular}{|c|c|c|c|c|}
\hline \multicolumn{5}{|c|}{ Shoot length } \\
\hline \multirow{2}{*}{ Treatments } & \multicolumn{2}{|c|}{$\mathbf{1}^{\text {st }}$ year } & \multicolumn{2}{c|}{$\mathbf{2}^{\text {nd }}$ year } \\
\cline { 2 - 5 } & Rainy season crop & Winter season crop & Rainy season crop & Winter season crop \\
\hline \multicolumn{5}{|c|}{ Pruning intensity } \\
\hline 0-node & 9.20 & 7.40 & 9.02 & 7.30 \\
\hline 6-node & 10.05 & 8.05 & 9.82 & 7.93 \\
\hline 8-node & 10.20 & 8.55 & 10.41 & 8.72 \\
\hline CD $(5 \%)$ & 11.07 & 9.23 & 11.21 & 9.56 \\
\hline
\end{tabular}

\section{Effect of pruning on reproductive attributes}

The data presented in Table 2 depicted that severe pruning minimized the span of flowering as severe pruning level of 8node recorded the shortest duration of flowering during both the rainy and winter season crops of both the years under study. Although, there was increment in fruit set with the enhanced severity of pruning, the results were non significant. Similar findings were reported by Sah et al. (2017) and Mahesh et al. (2016). The data presented in Table 3 showed that beyond 6-node pruning intensity, any subsequent increase in severity of pruning lead to reduction in fruit yield per tree. 6-node pruning intensity recorded significantly higher fruit yield per tree during both the cropping seasons of both the years. The lower fruit yield under 8-node pruning treatment as compared to pruning up to 6 nodes was perhaps due to reduction in the bearing area. Though the bearing area was the maximum under control trees and trees subjected to lighter pruning intensity (4-node), yet these treatments recorded lower fruit yield per tree than rest of the treatments. This might be attributed to the fact that there was more number of blind flower buds in trees subjected to such pruning intensities. The findings are found in consonance with those of Bajpai et al (1973), Gopikrishna (1981), Singh (2001), Mahesh et al (2016) and Sah et al (2017). According to Kumar and Rattanpal (2010), the decrease in number of fruit per plant is the consequence of pruning which reduced the fruiting area and on the other hand promoted the vegetative growth at the expense of reproductive growth.

Table 2: Influence of pruning intensity on duration of flowering (days) and per cent fruit set in Sardar guava

\begin{tabular}{|c|c|c|c|c|c|c|c|c|}
\hline \multirow{3}{*}{ Treatments } & \multicolumn{4}{|c|}{ Duration of flowering } & \multicolumn{4}{|c|}{ Per cent fruit set } \\
\hline & \multicolumn{2}{|c|}{$1^{\text {st }}$ year } & \multicolumn{2}{|c|}{$2^{\text {nd }}$ year } & \multicolumn{2}{|c|}{$1^{\text {st }}$ year } & \multicolumn{2}{|c|}{$2^{\text {nd }}$ year } \\
\hline & $\begin{array}{c}\text { Rainy season } \\
\text { crop }\end{array}$ & $\begin{array}{c}\text { Winter season } \\
\text { crop }\end{array}$ & $\begin{array}{c}\text { Rainy season } \\
\text { crop }\end{array}$ & $\begin{array}{c}\text { Winter season } \\
\text { crop }\end{array}$ & $\begin{array}{c}\text { Rainy season } \\
\text { crop }\end{array}$ & $\begin{array}{c}\text { Winter season } \\
\text { crop }\end{array}$ & $\begin{array}{l}\text { Rainy season } \\
\text { crop }\end{array}$ & $\begin{array}{c}\text { Winter season } \\
\text { crop }\end{array}$ \\
\hline \multicolumn{9}{|c|}{ Pruning intensity } \\
\hline 0 & 37 & 38 & 37 & 39 & 61.9 & 65.7 & 61.6 & 62.8 \\
\hline 4-node & 35 & 36 & 34 & 35 & 62.8 & 66.8 & 63.7 & 64.1 \\
\hline 6-node & 33 & 33 & 31 & 30 & 66.5 & 69.7 & 70.7 & 70.0 \\
\hline 8-node & 31 & 29 & 29 & 28 & 64.9 & 67.4 & 65.1 & 68.5 \\
\hline $\mathrm{CD}(5 \%)$ & 2.79 & 1.80 & 2.26 & 2.21 & NS & NS & NS & NS \\
\hline
\end{tabular}


Table 3: Influence of pruning intensity on fruit yield per tree $(\mathrm{kg})$ in Sardar guava

\begin{tabular}{|c|c|c|c|c|}
\hline \multicolumn{4}{|c|}{$\mathbf{1}^{\text {st }}$ year } & \multicolumn{2}{c|}{$\mathbf{2}^{\text {nd }}$ year } \\
\hline \multirow{2}{*}{ Treatments } & \multicolumn{3}{|c|}{ Wruit yield } \\
\cline { 2 - 5 } & Rainy season crop & Winter season crop & Rainy season crop & Winter season crop \\
\hline \multicolumn{4}{|c|}{ Pruning intensity } \\
\hline 0 & 45.9 & 47.1 & 48.6 & 54.0 \\
\hline 4-node & 56.7 & 56.0 & 55.3 & 59.0 \\
\hline 6-node & 69.5 & 72.4 & 73.6 & 76.5 \\
\hline 8-node & 59.0 & 60.6 & 60.5 & 63.1 \\
\hline CD (5\%) & 10.21 & 12.13 & 12.92 & 12.14 \\
\hline
\end{tabular}

\section{Effect of pruning on quality attributes}

The data presented in Table 4 depicted that there was significant increase in fruit weight with the increase in severity of pruning during the rainy and winter season crops of both the years. The severe pruning level, i.e. removal of shoot tip up to $8^{\text {th }}$ node registered higher fruit weight over the control and other pruning levels. The production of heavier fruits by trees subjected to severe pruning might be ascribed to the lesser crop load per tree and more nutrient supply to the limited fruit number. The discussion is further strengthened by the fact that trees subjected to severe pruning might have produced more leaves/ fruit ratio as compared to lightly pruned trees, thereby increasing the fruit weight. Similar results were quoted by Sundarajan and Muthuswamy (1964 b) and Bajpai et al. (1973)

Table 4: Effect of pruning intensity on fruit weight (g) in Sardar guava

\begin{tabular}{|c|c|c|c|c|}
\hline \multirow{2}{*}{ Treatments } & \multicolumn{3}{|c|}{$\mathbf{1}^{\text {st }}$ year } & \multicolumn{2}{c|}{$\mathbf{2}^{\text {nd }}$ year } \\
\cline { 2 - 5 } & Rainy season crop & Winter season crop & Rainy season crop & Winter season crop \\
\hline \multicolumn{4}{|c|}{ Pruning intensity } \\
\hline 0 & 122.9 & 126.3 & 115.6 & 123.6 \\
\hline 4-node & 127.4 & 133.9 & 125.3 & 133.7 \\
\hline 6-node & 134.4 & 143.3 & 137.5 & 144.6 \\
\hline 8-node & 145.4 & 154.4 & 149.5 & 12.90 \\
\hline CD (5\%) & 10.81 & 10.10 & 10.11 & \\
\hline
\end{tabular}

Further, data presented in Table 5 on fruit TSS/Acid ratio depicted that TSS/Acid ratio exhibited an increase with the increase in pruning intensity during both the years. 6- node and 8-node pruning levels recorded significantly higher
TSS/Acid ratio during the winter season crop of first year and rainy season crop of second year. On the whole, pruning to 8 nodes produced the fruits with higher TSS/Acid ratio.

Table 5: Effect of pruning intensity on fruit TSS/Acid ratio in Sardar guava

\begin{tabular}{|c|c|c|c|c|}
\hline \multicolumn{5}{|c|}{ TSS/Acid ratio } \\
\hline \multirow{2}{*}{ Treatments } & \multicolumn{2}{|c|}{$\mathbf{1}^{\text {st }}$ year } & \multicolumn{2}{c|}{$\mathbf{2}^{\text {nd }}$ year } \\
\cline { 2 - 5 } & Rainy season crop & Winter season crop & Rainy season crop & Winter season crop \\
\hline \multicolumn{5}{|c|}{ Pruning intensity } \\
\hline 0 & 30.00 & 27.02 & 30.26 & 31.13 \\
\hline 4-node & 30.10 & 28.58 & 30.61 & 32.19 \\
\hline 6-node & 34.53 & 34.07 & 35.64 & 34.72 \\
\hline 8-node & 34.69 & 34.72 & 37.82 & NS \\
\hline CD (5\%) & NS & 2.06 & 4.03 & \\
\hline
\end{tabular}

The data presented in Table 6 showed that there was a significant increase in ascorbic acid content of the fruits with the enhanced severity of pruning. 8- node pruning level along with pruning to 6-nodes recorded significantly higher Vitamin $\mathrm{C}$ than other pruning levels during the rainy season and winter season crops of both the years. On the whole, pruning to 8 nodes produced the fruits with higher Vitamin C. Similar results were quoted by Gill (1994), Sheikh and Hulmani (1996) and Kaur (1999).

Table 6: Effect of pruning intensity on Ascorbic acid content (mg/ $100 \mathrm{~g}$ of pulp weight) in Sardar guava

\begin{tabular}{|c|c|c|c|c|}
\hline \multicolumn{5}{|c|}{ Ascorbic acid content } \\
\hline \multirow{2}{*}{ Treatments } & \multicolumn{2}{|c|}{$1^{\text {st }}$ year } & \multicolumn{2}{|c|}{$2^{\text {nd }}$ year } \\
\hline & Rainy season crop & Winter season crop & Rainy season crop & Winter season crop \\
\hline \multicolumn{5}{|c|}{ Pruning intensity } \\
\hline 0 & 122.52 & 181.63 & 122.50 & 184.70 \\
\hline 4-node & 126.81 & 190.20 & 126.75 & 187.20 \\
\hline 6-node & 133.16 & 199.95 & 132.25 & 197.70 \\
\hline 8-node & 134.59 & 201.84 & 134.30 & 203.20 \\
\hline $\mathrm{CD}(5 \%)$ & 5.61 & 4.89 & 3.94 & 10.25 \\
\hline
\end{tabular}




\section{Conclusions}

There was enhancement in vegetative growth with the increase in pruning intensity. Severe pruning minimized the span of flowering as severe pruning level of 8-node pruning intensity recorded the shortest duration of flowering during both the rainy and winter season crops of both the years under study. Although, there was increment in fruit set with the enhanced severity of pruning, the results were non significant. 6-node pruning intensity recorded significantly higher fruit yield per tree during both the cropping seasons of both the years. There was significant increase in fruit weight with the increase in severity of pruning during the rainy and winter season crops of both the years. TSS/Acid ratio was not altered much by pruning intensity. On the other, there was a significant increase in ascorbic acid content of the fruits with the enhanced severity of pruning. On the whole, pruning to 6 nodes gave the highest fruit yield and accounted for production of fruits of good quality.

\section{References}

1. Anonymous. Horticultural Statistics at a Glance, 2018, 9.

2. Aravindakshan M. Effect of pruning on growth, flowering and fruit set of guava (Psidium guajava L.). Madras Agric J. 1953; 51:87-90.

3. Bajpai PN, Shukla HS, Chaturvedi AM. Effect of pruning on growth, yield and quality of guava (Psidium guajava L.) var. Allahabad Sufeda. Prog Hort. 1973; 5:73-79

4. Bhagawati R, Bhagawati K, Choudhary VK, Rajkhowa DJ, Sharma R. Effect of pruning intensities on the performance of fruit plants under mid hill condition of Eastern Himalayas: Case study on guava. Int. Let. Nat. Sci. 2015; 46:46-51.

5. Dasarathy TB. The guava. Madras Agric J. 1951; 38:52026.

6. Gill HS. Pruning studies on Sardar guava. M.Sc. Thesis, Punjab Agric Univ, Ludhiana, India, 1994.

7. Gopi Krishna NS. Studies on the effect of pruning on vegetative growth, flowering and fruiting in Sardar guava. M.Sc. Thesis, Univ. Agric. Sciences, Dharwad, India, 1981.

8. Gupta SN. Instant horticulture. Jain brothers, New Delhi, 2014, 206.

9. Jadhao BJ, Damke MM, Mahorkar VK, Dod VN, Wagh AP. Studies on effect of time and severity of pruning on growth and yield of guava (Psidium guajava L.) $c v$. Sardar. J Soils and Crops. 1998; 8(2):139-41.

10. Kaur R. Crop regulation by pruning in Sardar guava. M.Sc. Thesis, Punjab Agric Univ, Ludhiana, India, 1999.

11. Kumar Y, Rattanpal HS. Effect of pruning in guava planted at different spacing under Punjab condition. Indian J Hort. Sci. 2010; 67(special issue):115-119.

12. Mahesh RK, Jholgiker $P$, Mamatha NP, Ravi $P$, Shivanand MR, Kallappa SN. Effect of time and level of pruning on growth and yield of guava cv. Sardar under high density planting. Res. Environ. Life Sci. 2016; 9(7):849-853.

13. Radha T, Mathew L. Fruit crops. New India Publishing Agency, New Delhi, 2007, 59.

14. Sah H, Lal S, Negi SS. Effect of pruning on growth, flowering and yield in high density planting of guava. Int. J. Pure App. Biosci. 2017; 5(1):285-292.

15. Sheikh MK, Hulmani NC. Effect of severity of pruning on flowering and fruit quality of guava $c v$. Navalur. Prog Hort. 1996; 25:157-60.
16. Singh G. Response of vegetative growth, flowering and fruiting to pruning in Sardar guava. M.Sc. Thesis, Punjab Agric Univ, Ludhiana, India, 2001.

17. Singh G. Response of vegetative growth, flowering and fruiting to pruning in Sardar guava. M.Sc. Thesis, Punjab Agric Univ, Ludhiana, India, 2001.

18. Sundarajan S, Muthuswamy S. Preliminary studies on the effect of pruning in certain varieties of guava (Psidium guajava L.). Proc Acad Agric Sci Coiimbatore, Madras Agric J. 1964b; 51:81. 